\title{
Higher Parity, Pre-Pregnancy BMI and Rate of Gestational Weight Gain Are Associated with Gestational Diabetes Mellitus in Food Insecure Women
}

\author{
Heng Yaw Yong ${ }^{1}\left(\mathbb{D}\right.$, Zalilah Mohd Shariff ${ }^{1, *}$, Barakatun Nisak Mohd Yusof ${ }^{2} \mathbb{D}$, Zulida Rejali ${ }^{3}$, \\ Yvonne Yee Siang Tee ${ }^{4}$, Jacques Bindels ${ }^{5}$ and Eline M. van der Beek ${ }^{6}$
}

Citation: Yong, H.Y.; Mohd Shariff, Z.; Mohd Yusof, B.N.; Rejali, Z.; Tee, Y.Y.S.; Bindels, J.; van der Beek, E.M. Higher Parity, Pre-Pregnancy BMI and Rate of Gestational Weight Gain Are Associated with Gestational Diabetes Mellitus in Food Insecure Women. Int. J. Environ. Res. Public Health 2021, 18, 2694. https:// doi.org/10.3390/ijerph18052694

Academic Editor:

Agnieszka Zawiejska

Received: 27 January 2021

Accepted: 4 March 2021

Published: 7 March 2021

Publisher's Note: MDPI stays neutral with regard to jurisdictional claims in published maps and institutional affiliations.

Copyright: (c) 2021 by the authors Licensee MDPI, Basel, Switzerland. This article is an open access article distributed under the terms and conditions of the Creative Commons Attribution (CC BY) license (https:// creativecommons.org/licenses/by/ $4.0 /)$.
1 Department of Nutrition, Faculty of Medicine and Health Sciences, Universiti Putra Malaysia, Selangor 43400, Malaysia; yong_hy@upm.edu.my

2 Department of Dietetics, Faculty of Medicine and Health Sciences, Universiti Putra Malaysia, Selangor 43400, Malaysia; bnisak@upm.edu.my

3 Department of Obstetrics and Gynaecology, Faculty of Medicine and Health Sciences, Universiti Putra Malaysia, Selangor 43400, Malaysia; zulida@upm.edu.my

4 Danone Specialized Nutrition (Malaysia) Sdn. Bhd, Mid Valley City, Lingkaran Syed Putra, Kuala Lumpur 59200, Malaysia; yvonneyeesiang.tee@danone.com

5 Nutricia Research Foundation, Conradpark 3, 2441 AE Nieuwvee, The Netherlands; jacquesbindels@yahoo.de

6 Department of Pediatrics, University Medical Centre Groningen, University of Groningen, Hanzeplein 1, 9713 GZ Groningen, The Netherlands; e.m.van.der.beek@umcg.nl

* Correspondence: zalilahms@upm.edu.my

Abstract: Food insecurity may exacerbate adverse maternal health outcomes during pregnancy, however, this association has not been well established, particularly in the context of developing countries. This study aimed to identify the associations between household food insecurity and gestational diabetes mellitus (GDM) risk among urban pregnant women. Household food insecurity was assessed using the translated 10-item Radimer/Cornell hunger scale. Logistic regression models were used to estimate the associations between food insecurity status and GDM risk. About 35.6\% of women experienced food insecurity, with 25.2\% reported household food insecurity, $8.0 \%$ individual food insecurity, and $2.4 \%$ child hunger. Food insecure women were at significantly higher risk of developing GDM compared to food secure women (AOR $=16.65,95 \% \mathrm{CI}=6.17-24.98$ ). The significant association between food insecurity and GDM risk was influenced by pre-pregnancy BMI, parity and rate of GWG at second trimester. Food insecure women with parity $\geq 2$ (AOR $=4.21,95 \%$ $C I=1.98-8.92)$, overweight/obese BMI prior to pregnancy $(A O R=12.11,95 \% \mathrm{CI}=6.09-24.10)$ and excessive rate of GWG in the second trimester ( $\mathrm{AOR}=9.66,95 \% \mathrm{CI}=4.27-21.83$ ) were significantly more likely to develop GDM compared to food secure women. Food insecurity showed strong association with GDM risk in that the association was influenced by maternal biological and physical characteristics. Multipronged interventions may be necessary for food insecure pregnant women who are not only at risk of overweight/obesity prior to pregnancy but also may have excessive gestational weight gain, in order to effectively reduce GDM risk.

Keywords: hemoglobin; hemoglobin change; gestational diabetes mellitus; pregnancy

\section{Introduction}

Household food insecurity, i.e., the inability to obtain nutritious and safe foods in socially acceptable ways, is increasingly recognized as an independent risk factor for many poor health outcomes among women [1]. Studies have shown that women living in food insecure households had higher prevalence rates of overweight $[2,3]$ and related health complications [4-6]. Previous studies reported that food insecurity during pregnancy was associated with greater gestational weight gain (GWG), a greater observed-to-recommended weight gain ratio and increased risk for developing gestational diabetes mellitus (GDM) [7]. 
Research from both animal and human studies suggest that being worried, concerned or anxious about not having enough food, or uncertainty about one's ability to obtain food is associated with stress-related weight gain $[3,8]$. Women from food-insecure households may become economically dependent on low-cost, processed, high-calorie and low-nutrient dense foods in order to stretch the household budget. The consumption of these high energy dense foods over time may lead to excessive weight gain [9].

Among non-pregnant adults, household food insecurity may both predispose to and exacerbate the manifestations of diabetes mellitus [4-6]. Household food insecurity was associated with the risk of diabetes after controlling for weight status and other potential confounders [4,5]. Among diabetic adults, household food insecurity was further associated with poor diabetes management [6]. People living in food insecure environment with limited budget often have limited control over their living environments, which can affect their ability to access and prepare healthy food. For example, they are only able to buy foods from low-income neighbourhoods (convenience stores), which carry low-nutrition foods or they may have difficulty to find accommodations with access to a stove and a refrigerator, which are needed to prepare meals, and thus, they often choose easier-to-access food (e.g., canned, pre-cooked) [10,11]. Diets common in food insecure households, such as energy-dense (e.g., refined grains, added sugars, fats), canned or pre-cooked foods may increase dietary glycemia load, and further increase susceptibility to one or more chronic illness, including type 2 diabetes risk [12-14].

In Malaysia, the prevalence of overweight and obesity (BMI $\geq 25.0 \mathrm{~kg} / \mathrm{m}^{2}$ ) among women aged $\geq 18$ years old increased by $8.7 \%$ in the period between 2006 and 2019 [15,16]. With the increasing prevalence of overweight and obesity among women of childbearing age, the risks of having excessive GWG and/or developing GDM are high. A study in rural areas of a state on the east coast of Malaysia showed that about $83.9 \%$ of non-pregnant reproductive-age women experienced some forms of food insecurity [17] and hypothesized that food insecurity predisposed these women to excessive weight gain. Entering pregnancy with higher BMI may increase the risk of excessive GWG since pregnancy is a period of adapted physiology and metabolism as well as actual and perceived increase in food intake, thereby increasing the risk of GDM. This study aimed to understand the association between food insecurity and risk of GDM, in particular the specific factors that could influence the association among women living in urban areas. This information is pertinent to the development of public health strategies to prevent GDM in food insecure populations.

\section{Materials and Methods}

This study used data from the Seremban Cohort Study (SECOST) that examined the determinants and pregnancy outcomes of maternal hyperglycemia. Between January 2013 and December 2013, a total of 737 pregnant women were recruited through maternal and child health $(\mathrm{MCH})$ clinics in Seremban district, Negeri Sembilan. All women were recruited before 14th weeks of gestation and followed through their pregnancy. Women completed face-to-face interviews for information on socio-demographics, dietary intake, physical activity and a retrospective measure of food insecurity status [18]. Of the 737 women enrolled in the study,

The final sample comprised 452 pregnant women (61.3\%) who completed follow-up, including the oral glucose tolerance test (OGTT), around 28-32 weeks of gestation. A total of 285 women were excluded due to abnormal maternal glycemia $(n=57)$ at study enrolment signalling pre-pregnancy type 2 diabetes, miscarriage or stillbirth $(n=59)$, withdrawal for health/personal reasons $(n=65)$, transfer to other clinics or lost contact $(\mathrm{n}=102)$, and failure to undergo OGTT $(\mathrm{n}=2)$ (Figure 1$)$. 


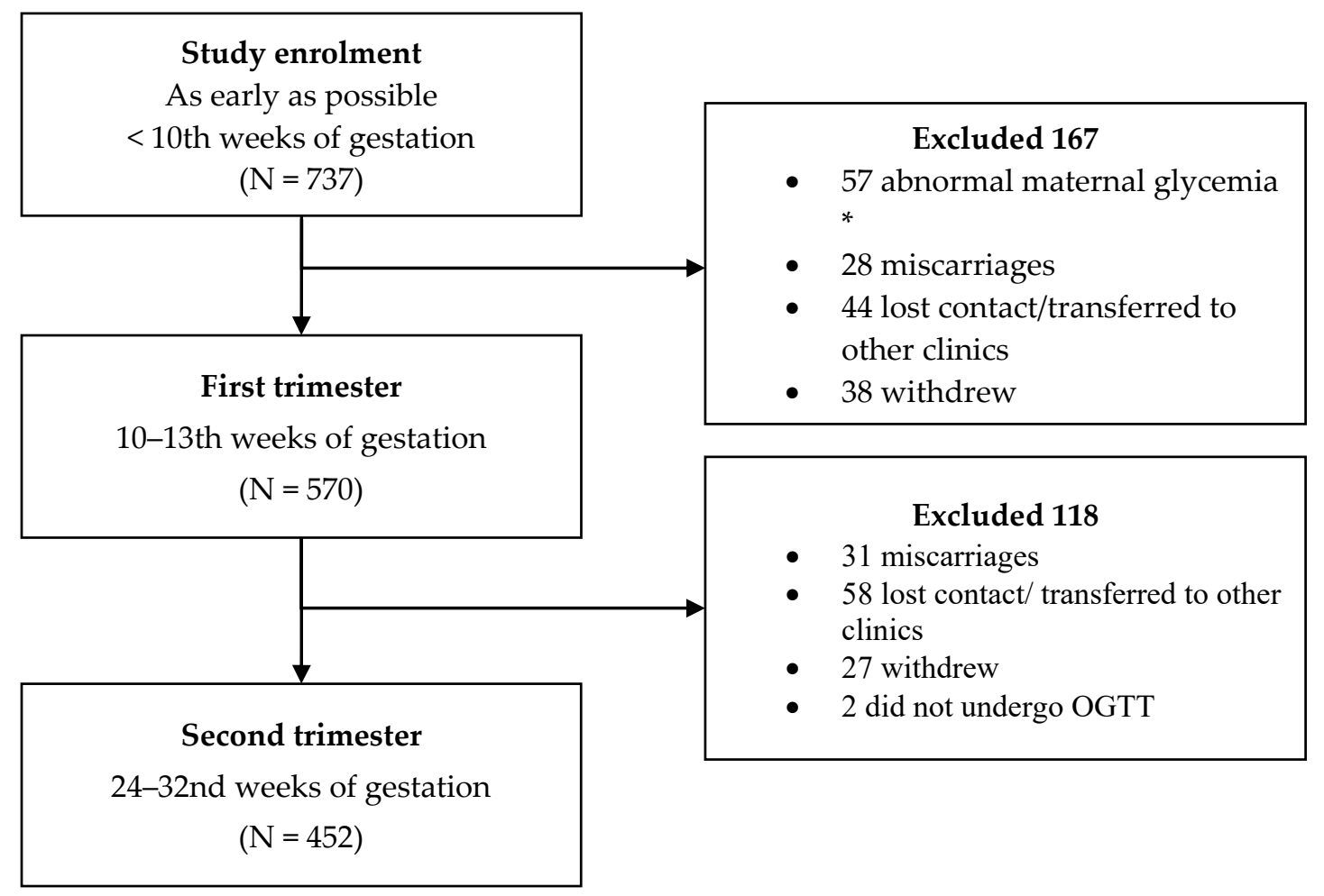

* Abnormal maternal glycemia defined as either or both FPG $\geq 5.6 \mathrm{mmol} / \mathrm{l}$ or $2 \mathrm{hPG} \geq 7.8 \mathrm{mmol} / \mathrm{l}$ (MOH, 2015).

Figure 1. Recruitment of study respondents.

\subsection{Food Insecurity}

Household food insecurity was assessed between 24 and 32nd weeks of gestation using the 10-item Radimer/Cornell hunger scale [19], which was translated into Bahasa Malaysia [20] (Table 1). Women were asked about the individuals in their households experiencing food insecurity during the woman's pregnancy. Food insecurity consists of four components: quantity of food, quality of food, food acceptability and certainty of getting food. According to the conceptualization of the Radimer/Cornell Scale, as the problem worsens, household food insecurity representing uncertainty and anxiety about food at the household level is experienced first (mild food insecurity), followed by adult food insecurity (or moderate food insecurity) characterized by decreased quality and quantity of food eaten by adults [21]. Child hunger (or severe food insecurity) is the most severe problem that is characterized by decreased quantity and quality of food eaten by children. Based on the data on the items of the Radimer/Cornell Scale, women were classified into four mutually exclusive categories with increasing severity, e.g., food secure, household food insecure, adult food insecure and child hunger. 
Table 1. The 10 items in the Radimer/Cornell hunger scale.

\begin{tabular}{cl}
\hline Level & \multicolumn{1}{c}{ Items } \\
\hline \multirow{3}{*}{ Household } & 1. I worry whether my food will run out before I get money to buy more. \\
& 2. The food that I bought just didn't last, and I didn't have money to get more. \\
& 3. I ran out of the foods that I needed to put together a meal and I didn't have money to get more food. \\
& 4. We eat the same thing for several days in a row because we only have a few different kinds of food at \\
& hand and don't have money to buy more.
\end{tabular}

Noted. Food secure: negative answers (never or not true) to all items. Household insecure: positive answers (sometimes true or often true) to one or more items (1-4) but not to adult or child level items. Individual insecure: positive answers to one or more of items (5-8) but not to items (9-10). Child hunger: positive answer to one or more items (9-10).

\subsection{Anthropometric Measurements}

Maternal height was measured at study enrolment, while weight was measured at enrolment and each study visits using a standard instrument (SECA digital weighing scale and SECA body meter) and standard procedures. Women were requested to recall pre-pregnancy body weight (current pregnancy). Pre-pregnancy BMI was calculated as weight in kilograms divided by the square of height in meters and classified according to World Health Organization (WHO)'s cut-off points respectively: underweight $\left(<18.5 \mathrm{~kg} / \mathrm{m}^{2}\right)$, normal weight $\left(18.5-24.9 \mathrm{~kg} / \mathrm{m}^{2}\right)$, overweight $\left(25.0-29.9 \mathrm{~kg} / \mathrm{m}^{2}\right)$ and obese $\left(\geq 30.0 \mathrm{~kg} / \mathrm{m}^{2}\right)[22,23]$. Weight in the first, and second trimester was measured as the closest measurement to 12th weeks of gestation (10-13th weeks) and to 26 weeks of gestation (range 24-32nd weeks, respectively. Estimates of the GWG at first trimester and rate of GWG at second trimester were then classified as gaining below (inadequate GWG), within (adequate GWG) and above (excessive GWG) the recommendation by the Institute of Medicine (IOM) [24].

\subsection{Gestational Diabetes Mellitus}

All pregnant women were required to take a standard 2-h $75 \mathrm{~g}$ oral glucose tolerance test (OGTT) between 28th to 32nd week of gestation [23]. GDM at study period was diagnosed if either or both fasting plasma glucose (FPG) was $\geq 5.6 \mathrm{mmol} / \mathrm{L}$ or 2-h plasma glucose ( $2 \mathrm{hPG}$ ) was $\geq 7.8 \mathrm{mmol} / \mathrm{L}$ according to the Ministry of Health $(\mathrm{MOH})$ Malaysia guideline [23].

\subsection{Other Variables}

Socio-demographic information obtained included current age, education level, ethnicity, occupation status, monthly household income, and household size. Obstetrical information (e.g., gravidity and parity) was obtained from medical records.

\subsection{Statistical Analysis}

All statistical analyses were performed using IBM SPSS Statistics for Windows, Version 23.0 [25]. Continuous variables were expressed as the means and standard deviations, while categorical variables as absolute frequencies and percentages. As there were few women in the individual insecure $(n=36)$ and child hunger $(n=11)$ categories, the response categories for food insecurity were combined into two groups: food secure and food insecure. Multiple logistic regression was used to determine the association between food security status and the risk of GDM, adjusted for covariates. Further interaction analysis was performed on age, family history of DM, income, parity, rate of GWG and prepregnancy BMI. A stratified analysis was performed further for any significant interaction 
term. Adjusted odds ratios (OR) and 95\% confidence intervals (CIs) were calculated. A $p$-value of 0.05 was set as statistically significant.

\section{Results}

\subsection{Characteristics of Subjects}

Table 2 shows the characteristics of the 452 pregnant women. The mean age of women was $30.3 \pm 4.5$ years, with $51.3 \%$ were aged more than 30 years. Majority of women were Malays $(88.9 \%)$, had attained secondary and lower education $(45.8 \%)$, were employed (69.0\%), had low household incomes (63.7\% reported less than RM 3860/920.69 USD), and had a household containing 3-4 people (50.7\%). Most women had no medical history of GDM (93.1\%) or family history of diabetes mellitus (75.7\%). The mean height, prepregnancy weight and pre-pregnancy BMI were $1.56 \pm 0.06 \mathrm{~m}, 58.72 \pm 13.36 \mathrm{~kg}$, and $23.96 \pm 4.99 \mathrm{~kg} / \mathrm{m}^{2}$, respectively. Slightly more than half (53.5\%) of women were in the normal weight range, $22.4 \%$ overweight, $13.5 \%$ obese and $10.6 \%$ underweight. While most women $(90.3 \%)$ had inadequate GWG at the first trimester, the proportion of women with inadequate $(33.6 \%)$, adequate $(32.8 \%)$ and excessive $(33.6 \%)$ rate of GWG at the second trimester were equally distributed. Approximately $35.6 \%$ of women revealed that they had experienced of food insecurity, with $25.2 \%(\mathrm{n}=161)$ reporting household food insecurity, $8.0 \%(\mathrm{n}=36)$ individual food insecurity, and $2.4 \%(\mathrm{n}=11)$ child hunger. About $10.6 \%$ of the women were diagnosed with GDM.

Table 2. Characteristics of women $(\mathrm{N}=452)$.

\begin{tabular}{|c|c|c|}
\hline Characteristics & n (\%) & Mean \pm SD \\
\hline Age (years) & & $30.30 \pm 4.50$ \\
\hline$\leq 30$ & $220(48.7)$ & \\
\hline$>30$ & $232(51.3)$ & \\
\hline \multicolumn{3}{|l|}{ Ethnicity } \\
\hline Malay & $402(88.9)$ & \\
\hline Non-Malay & $50(11.1)$ & \\
\hline Education level (years) & & $12.96 \pm 2.39$ \\
\hline Secondary and lower & $207(45.8)$ & \\
\hline STPM/Matric/Diploma/Certificate & $148(32.7)$ & \\
\hline Tertiary and above & $97(21.5)$ & \\
\hline \multicolumn{3}{|l|}{ Occupation status } \\
\hline Unemployed & $140(31.0)$ & \\
\hline Employed & $312(69.0)$ & \\
\hline Monthly household income (RM) $¥$ & & $3705.72 \pm 2053.72$ \\
\hline Low $(<3860)$ & $288(63.7)$ & \\
\hline Middle (3860-8319) & $150(33.2)$ & \\
\hline $\operatorname{High}(\geq 8320)$ & $14(3.1)$ & \\
\hline Household size & & $3.77 \pm 1.61$ \\
\hline$\leq 2$ & $108(23.9)$ & \\
\hline $3-4$ & $229(50.7)$ & \\
\hline$\geq 5$ & $115(25.4)$ & \\
\hline Gravidity & & $2.46 \pm 1.48$ \\
\hline 1 & $144(31.9)$ & \\
\hline 2 & $127(28.1)$ & \\
\hline$\geq 3$ & $181(40.0)$ & \\
\hline Parity & & $1.23 \pm 1.00$ \\
\hline 0 & $163(36.1)$ & \\
\hline $1-2$ & $219(48.5)$ & \\
\hline$\geq 3$ & $70(15.5)$ & \\
\hline
\end{tabular}


Table 2. Cont.

\begin{tabular}{lcc}
\hline \multicolumn{1}{c}{ Characteristics } & n (\%) & Mean \pm SD \\
\hline Medical history of gestational diabetes mellitus (GDM) & $421(93.1)$ & \\
No & $31(6.9)$ & \\
Yes & $342(75.7)$ & \\
\hline Family history of diabetes mellitus & $110(24.3)$ & \\
No & & $1.56 \pm 0.06$ \\
Yes & $172(38.0)$ & \\
\hline Height (m) & $131(29.0)$ & \\
$<1.55$ & $149(33.0)$ & \\
$1.55-1.58$ & & \\
$\geq 1.59$ & $48.72 \pm 13.36$ \\
\hline Pre-pregnancy weight $(\mathrm{kg})$ & $242(53.5)$ & \\
Pre-pregnancy BMI $\left(\mathrm{kg} / \mathrm{m}^{2}\right)$ & $101(22.4)$ & \\
Underweight $(<18.5)$ & $61(13.5)$ & \\
Normal (18.5-24.9) & & \\
Overweight $(25.0-29.9)$ & $408(90.3)$ & \\
Obese ( $\geq 30.0)$ & $44(9.7)$ & \\
\hline Gestational weight gain $(\mathrm{GWG})$ at first trimester & $0.16 \pm 0.04$ \\
Inadequate & $152(33.6)$ & \\
\hline Adequate & $148(32.8)$ & \\
Excessive & $152(33.6)$ & \\
\hline Rate of GWG at second trimester(kg/week) & & \\
Inadequate & & \\
Adequate & & \\
Excessive & & \\
\hline
\end{tabular}

Physical activity and dietary intake at the second trimester

\begin{tabular}{|c|c|c|}
\hline Total physical activity (METs hour/week) & & $265.34 \pm 117.25$ \\
\hline Energy (kcal/day) & & $2172 \pm 896.90$ \\
\hline \multicolumn{3}{|l|}{ Food security } \\
\hline Food secure & $291(64.4)$ & \\
\hline Food insecure & $161(35.6)$ & \\
\hline Household insecure & $114(25.2)$ & \\
\hline Individual insecure & $36(8.0)$ & \\
\hline Child hunger & $11(2.4)$ & \\
\hline \multicolumn{3}{|l|}{$\begin{array}{l}\text { Maternal glucose level oral glucose tolerance test } \\
\text { (OGTT) }(\mathrm{mmol} / \mathrm{l})\end{array}$} \\
\hline Gestational age at OGTT performed (weeks) & & $28.01 \pm 0.24$ \\
\hline Fasting plasma glucose (FPG) & & $4.38 \pm 0.54$ \\
\hline 2-h plasma glucose (2hPG) & & $5.94 \pm 1.51$ \\
\hline GDM according to $\mathrm{MOH}$ criteria $\ddagger$ & $48(10.6)$ & \\
\hline GDM according to IADPSG criteria $\S$ & $57(12.6)$ & \\
\hline
\end{tabular}

\subsection{Associations between Household Food Security Status and the Risk of GDM}

Table 3 shows the associations between household food security status and the risk of GDM. Women from food insecure households had significantly higher risk of GDM ( $\mathrm{AOR}=16.65,95 \% \mathrm{CI}=6.17-24.98)$ compared to food secure women. Additionally, there were significant interactions between household food insecurity with parity, pre-pregnancy $\mathrm{BMI}$, and the rate of GWG in the second trimester. Table 4 further shows the AORs and 95\% CI for the associations between household food security status and GDM risk stratified by parity, pre-pregnancy BMI and rate of GWG in the second trimester. Food insecure 
women with parity of two and above ( $\mathrm{AOR}=4.21,95 \% \mathrm{CI}=1.98-8.92)$, overweight/obesity $(\mathrm{AOR}=12.11,95 \% \mathrm{CI}=6.09-24.10)$ and excessive rate of GWG in the second trimester $(\mathrm{AOR}=9.66,95 \% \mathrm{CI}=4.27-21.83)$ were at significantly higher risk of GDM compared to food secure women.

Table 3. Unadjusted and adjusted odds ratio (OR) and 95\% confidence intervals (95\% CI) for associations between food security status and gestational diabetes mellitus (GDM) $(n=452)$.

\begin{tabular}{|c|c|}
\hline Variable & $\begin{array}{c}\text { GDM }(n=48) \\
\text { OR }[95 \% \text { CI] }\end{array}$ \\
\hline \multicolumn{2}{|l|}{ Food security status ${ }^{a}$} \\
\hline Food secure & 1.00 \\
\hline Food insecure & $16.65[6.17-24.98]^{* *}$ \\
\hline \multicolumn{2}{|l|}{ Interaction terms } \\
\hline Food insecure * pre-pregnancy BMI & $1.12[1.08-1.15]^{* *}$ \\
\hline Food insecure * parity & $1.72[1.33-2.23]^{* *}$ \\
\hline Food insecure * rate of GWG (2nd trimester) & $17.93[10.35-22.15]^{* *}$ \\
\hline
\end{tabular}

Table 4. Adjusted odds ratio (OR) and 95\% confidence intervals (95\% CI) for associations between household food security and gestational diabetes mellitus (GDM) stratified by parity, pre-pregnancy BMI and rate of GWG (2nd trimester).

\begin{tabular}{|c|c|c|c|c|c|c|}
\hline & \multicolumn{2}{|c|}{ Parity $^{a}$} & \multicolumn{2}{|c|}{ Pre-pregnancy BMI ${ }^{b}$} & \multicolumn{2}{|c|}{ Rate of GWG (2nd trimester) ${ }^{a}$} \\
\hline & $<2(n=297)$ & $\geq 2(n=155)$ & UW/NW (n = 290) & OW/OB $(n=162)$ & Inadequate $(\mathrm{n}=152)$ & Excessive $(\mathrm{n}=152)$ \\
\hline & \multicolumn{6}{|c|}{ Adjusted OR [95\% CI] } \\
\hline Food secure & 1.00 & 1.00 & 1.00 & 1.00 & 1.00 & 1.00 \\
\hline Food insecure & $0.65[0.08-6.80]$ & $4.21[1.98-8.92]^{*}$ & 1.58 [0.76-3.30] & $12.11[6.09-24.10]^{* *}$ & 0.69 [0.05-9.72] & $9.66[4.27-21.83]^{* *}$ \\
\hline
\end{tabular}

a Adjusted by age, family history of DM, pre-pregnancy BMI, income, energy intake and physical activity level. ${ }^{b}$ Adjusted by age, parity, family history of DM, income, energy intake and physical activity level. ${ }^{*} p<0.05,{ }^{* *} p<0.05$.

\section{Discussion}

The present study showed that food insecure women had significantly higher risk of GDM compared to food secure women. However, the association was specific for women with higher parity, overweight/obesity, and excessive rate of GWG in the second trimester. Previous studies among pregnant women $[7,26]$ and general population $[10,11]$ have also shown that GDM and T2DM were more prevalent in food insecure than food secure households. Although data on household food insecurity and the risk of GDM are scarce $[7,26]$, studies in low income population (e.g., Pakistan, Sri Lanka, Africa, Turkey,) have also reported an association between higher parity, overweight/obesity and excessive GWG with a higher risk of GDM [27-32]. As food insecurity is prevalent in low-income population, these findings lend support to food insecurity as an important risk factor for GDM which could be dependent or independent on other risk factors of GDM.

The association between food insecurity and GDM could, at least in part, be explained by unhealthy diets or eating patterns due to limited food budget or income. Food insecure individuals are more prone to consumption of high energy dense foods with low nutritional value [33], and dysregulated eating. The latter is characterized by overconsumption of food when foods are available, and food restriction when food shortages exist [34], as well as emotional eating, which is triggered by emotional distress caused by lack of access to adequate foods $[35,36]$. The observed unhealthy diets and/or eating patterns could disrupt normal physiology and metabolic regulation and further contribute the development of GDM [20,37]. Previous studies showed that food assistance programs might play a role in dysregulated eating as they are typically disbursed once monthly and could lead to a monthly cycle of feast and famine [38,39]. Studies on recipients of the Supplemental Nutrition Assistance Program (SNAP), the largest food assistance program in the United 
States, found that recipients were more likely to report days with no eating [40] and had a lower diet quality [41] at the end of the benefit month than non-recipients. As the present study did not assess whether the women received any food assistance programs, it is unknown whether the association between food insecurity and GDM risk is influenced by such programs. A low intake of fruit and vegetables could deprive food insecure individuals of the protective effects of essential nutrients against diseases such as diabetes, which occur as a result of poor nutrition [16,39]. It is also possible that women with food insecurity have limited knowledge of nutrition, and less time and resources to prepare or engage in healthy eating.

It has been suggested that increasing body fat storage is a physiologically regulated response by the body to a threatened food supply, which occurs specifically in women with low socioeconomic status [42,43]. This could explain why food insecure women are predisposed to overweight or obesity at pre-pregnancy, a well-recognized risk factor for excessive GWG and GDM. Further analysis of the present data also showed that the association between food insecurity and excessive GWG is indeed pronounced among overweight/obese women $(\mathrm{AOR}=7.76,95 \% \mathrm{CI}=2.08-29.02)$ compared to underweight $/$ normal weight women $(\mathrm{AOR}=2.00,95 \% \mathrm{CI}=0.52-7.70)$. The association between overweight/obese food insecure women and higher GWG could be due to unhealthy eating behavior [44], whereby food insecure women tend to choose high-calorie energy dense but low-nutrient foods (lower protein and micronutrients containing foods, but higher intake of energy dense snack foods) [45,46]; and psychological or emotional stress or depression [47]. The association could also be explained by the availability of and accessibility to fast-food chains and the ubiquitous food stalls or hawker foods in Malaysia [48]. In particular, hawker stalls and fast-food chains are associated with foods that are fried or deep-fried, high in sodium and prepared with high-fat containing ingredients e.g., coconut milk [49]. Additionally, the local snacks or delicacies available at food/hawker stalls or at morning and night markets are high in fat and sugar. Such energy dense foods, eaten outside the normal meal moments, may contribute to excessive daily energy intake. Laraia et al. (2013) further showed that food insecure pregnant women with a dietary restraint, defined as the extent to which a person thinks about her diet and weight and tries to restrict dietary intake before pregnancy, had in fact the greatest GWG [44]. Future studies should further investigate the details of eating patterns of women with food insecurity during pregnancy, such as dietary change before and during pregnancy, as well as its association with health outcomes.

More than one-third of pregnant women (35.6\%) in this study experienced food insecurity. This finding is consistent with studies conducted in developing countries, such as Iran (30.9-35.1\%) [50,51] and Ethiopia (41.0\%) [52], but is higher than that of studies conducted in developed countries, in which $2.3-24.0 \%$ of pregnant women were found to face food insecurity $[7,44]$. The difference between studies may be attributed to the tools used to assess food insecurity (e.g., 18-item core food security module, 9-item household food insecurity access scale and 10-item Radimer/Cornell hunger scale), and the characteristics of the study populations (e.g., economic status, education level, and accessibility of food). This finding further reiterates existing evidence that a relatively high proportion of pregnant women in developing countries experience some level of food insecurity during pregnancy. From a health perspective, food insecurity is mainly caused by the problem of food access, whereby having insufficient resources (e.g., lack of purchasing power, lack of physical access) to obtain appropriate foods for a nutritious diet and the problem of food utilization (e.g., diet with adequate energy and nutrients, safe drinking water, proper sanitation etc.) [53]. Thus, effective health programs or interventions, such as nutrition assistance programs, referrals to local food pantries, and nutrition education initiatives, especially among vulnerable groups (e.g., overweight/obese, low-income pregnant women) are needed to ensure optimal maternal and child health.

Several study limitations should be considered. The study findings cannot be generalized to all pregnant women in Malaysia as this study was conducted among pregnant women attending antenatal care at the MCH clinics in Seremban Districts. For example, 
food insecurity might be overestimated as most of the pregnant women attending $\mathrm{MCH}$ clinics (government-funded clinics) are from low to middle income households. The use of the Radimer/Cornell hunger scale to measure food insecurity might not represent the total burden of food insecurity, as this scale did not address several dimensions of food insecurity such as psychological (e.g., stress, depression) and social reasons (e.g., alienation). Additionally, this scale does not capture reasons beyond financial constraints and limited resources [54,55]. The present study did not investigate psychological factors (e.g., stress, anxiety, depression, stressful life events) that could be associated with food insecurity and further leading to emotional eating and GDM. Furthermore, the diagnosis of GDM was based on the local diagnostic criteria. Despite these limitations, this study provides support for the important role of food insecurity in the development of GDM among urban women from predominantly middle- and low-income households in Malaysia.

\section{Conclusions}

Food insecurity is an important risk factor for GDM in this sample of urban Malay women. The association was particularly pronounced among women with parity of 2 or above, overweight/obesity and excessive GWG. While further research is needed to understand the underlying mechanisms driving the effect of food insecurity on GDM, these data do provide opportunities to develop public health and community interventions. Reproductive age women, including pregnant women from food insecure households, should be targeted for specific interventions that address risk factors of diet-related noncommunicable diseases. For example, nutrition advice or counselling to increase the use of healthy foods (e.g., accessible, nutrient-dense, diverse types and affordable foods) should be made available not only during pregnancy but also during the postpartum period and prior to subsequent pregnancy.

Author Contributions: Z.M.S. is the project leader of the SECOST study and designed the project with H.Y.Y. H.Y.Y. conducted the literature search, data collection, statistical analyses and wrote the first draft of the paper. B.N.M.Y., Z.R., Y.Y.S.T. and J.B. contributed to methodology and resources. E.M.v.d.B. and Z.M.S. revised the subsequent drafts for important intellectual content and approved the final version of the paper to be published. All authors have read and agreed to the published version of the manuscript.

Funding: This work was supported by the Danone Dumex (Malaysia) Sdn Bhd [6368500].

Institutional Review Board Statement: The study was conducted according to the guidelines of the Declaration of Helsinki and approved by the Medical Research Ethics Committee (MREC), Universiti Putra Malaysia (UPM/FPSK/100-9/2-MJKEtika) and the Medical Research Ethics Committee (MREC), Ministry of Health Malaysia (KKM/NIHSEC/08/0804/P12-613).

Informed Consent Statement: Written informed consent has been obtained from the participants prior to enrollment in the study.

Data Availability Statement: The data presented in this study are available on request from the corresponding author. The data are not publicly available due to the Medical Research Ethics Committee (MREC), Ministry of Health Malaysia, has imposed on the restriction of disclosure data contain potentially identifying patient information.

Acknowledgments: The authors would like to acknowledge the nurses, staff, and officials in $\mathrm{MCH}$ clinics Seremban districts, Negeri Sembilan for their support and assistance during data collection.

Conflicts of Interest: Jacques Bindels and Yvonne Yee Siang are employees of Nutricia Research Foundation (The Netherlands) and of Danone Specialized Nutrition (Malaysia), respectively. Eline van der Beek was employed by Danone Nutricia Research at the time of the study was conducted (former employee). None of the authors had any personal or financial conflict of interest.

\section{References}

1. Laraia, B.; Vinikoor-Imler, L.C.; Siega-Riz, A.M. Food insecurity during pregnancy leads to stress, disordered eating, and greater postpartum weight among overweight women. Obesity 2015, 23, 1303-1311. [CrossRef] 
2. Holben, D.H.; Pheley, A.M. Diabetes risk and obesity in food-insecure households in rural Appalachian Ohio. Prev. Chronic Dis. A 2006, 3, 82 .

3. Wilde, P.E.; Peterman, J.N. Individual weight change is associated with household food security status. J. Nutr. 2006, 136, 1395-1400. [CrossRef]

4. $\quad$ Seligman, H.K.; Bindman, A.B.; Vittinghoff, E.; Kanaya, A.M.; Kushel, M.B. Food Insecurity is associated with diabetes mellitus: Results from the National Health Examination and Nutrition Examination Survey (NHANES) 1999-2002. J. Gen. Intern. Med. 2007, 22, 1018-1023. [CrossRef]

5. Maddigan, S.L.; Feeny, D.H.; Majumdar, S.R.; Farris, K.B.; Johnson, J.A. Understanding the determinants of health for people with type 2 diabetes. Am. J. Public Health 2006, 96, 1649-1655. [CrossRef] [PubMed]

6. Nelson, K.; Cunningham, W.; Andersen, R.; Harrison, G.; Gelberg, L. Is food insufficiency associated with health status and health care utilization among adults with diabetes? J. Gen. Intern. Med. 2001, 16, 404-411. [CrossRef]

7. Laraia, B.A.; Siega-Riz, A.M.; Gundersen, C. Household food insecurity is associated with self-reported pregravid weight status, gestational weight gain, and pregnancy complications. J. Am. Diet. Assoc. 2010, 110, 692-701. [CrossRef] [PubMed]

8. Carr, K.D. Food scarcity, neuroadaptations, and the pathogenic potential of dieting in an unnatural ecology: Binge eating and drug abuse. Physiol. Behav. 2011, 104, 162-167. [CrossRef] [PubMed]

9. Drewnowski, A. Obesity and the food environment: Dietary energy density and diet costs. Am. J. Prev. Med. 2004, 27, 154-162. [CrossRef]

10. Seligman, H.K.; Laraia, B.A.; Kushel, M.B. Food insecurity is associated with chronic disease among low-income NHANES participants. J. Nutr. 2009, 140, 304-310. [CrossRef]

11. Gucciardi, E.; Vahabi, M.; Norris, N.; Del Monte, J.P.; Farnum, C. The intersection between food insecurity and diabetes: A review. Curr. Nutr. Rep. 2014, 3, 324-332. [CrossRef]

12. Weigel, M.M.; Armijos, R.X.; Hall, Y.P.; Ramirez, Y.; Orozco, R. The household food insecurity and health outcomes of U.S.-Mexico border migrant and seasonal farmworkers. J. Immigr. Minor. Health 2007, 9, 157-169. [CrossRef]

13. Fitzgerald, N.; Hromi-Fiedler, A.; Segura-Pérez, S.; Pérez-Escamilla, R. Food insecurity is related to increased risk of type 2 diabetes among Latinas. Ethn. Dis. 2011, 21, 328-334.

14. Gucciardi, E.; Vogt, J.A.; DeMelo, M.; Stewart, N.E. Exploration of the relationship between household food insecurity and diabetes in Canada. Diabetes Care 2009, 32, 2218-2224. [CrossRef] [PubMed]

15. IPH. The Third National Health and Morbidity Survey (2006); Ministry of Health Malaysia, Institute for Public Health: Kuala Lumpur, Malaysia, 2008.

16. Institute for Public Health (IPH). National Health and Morbidity Survey (NHMS) 2019: Volume I: NCDs-Non-Communicable Diseases: Risk Factors and other Health Problems; Ministry of Health Malaysia, National Institutes of Health: Shah Alam, Selangor, 2020.

17. Ihab, A.; Rohana, A.; Manan, W.W.; Suriati, W.W.; Zalilah, M.; Rusli, A.M. Nutritional outcomes related to household food insecurity among mothers in rural Malaysia. J. Health Popul. Nutr. 2014, 31, 480-489. [CrossRef] [PubMed]

18. Yong, H.Y.; Shariff, Z.M.; Rejali, Z.; Yusof, B.N.M.; Yasmin, F.; Palaniveloo, L. Seremban Cohort Study (SECOST): A prospective study of determinants and pregnancy outcomes of maternal glycaemia in Malaysia. BMJ Open 2018, 8, e018321. [CrossRef] [PubMed]

19. Kendall, A.; Olson, C.M.; Frongillo, E.A. Validation of the Radimer/Cornell measures of hunger and food insecurity. J. Nutr. 1995, 125, 2793-2801.

20. Shariff, Z.M.; Sulaiman, N.; Jalil, R.A.; Yen, W.C.; Yaw, Y.H.; Taib, M.N.M.; Kandiah, M.; Lin, K.G. Food insecurity and the metabolic syndrome among women from low income communities in Malaysia. Asia Pac. J. Clin. Nutr. 2014, $23,138-147$.

21. Kendall, A.; Olson, C.M.; Frongillo, E.A. Relationship of hunger and food insecurity to food availability and consumption. J. Am. Diet. Assoc. 1996, 96, 1019-1024. [CrossRef]

22. WHO. Physical Status: The Use and Interpretation of Anthropometry. Report of a WHO Expert Committee; WHO Technical Report Series No. 854; WHO: Geneva, Switzerland, 1995.

23. Ministry of Health Malaysia. Perinatal Care Manual, 3rd ed.; Division of Family Health Development, MOH: Putrajaya, Malaysia, 2013.

24. Institute of Medicine. Weight Gain During Pregnancy: Reexamining the Guidelines; National Academies Press: Washington, DC, USA, 2009.

25. IBM Corp. IBM SPSS Statistics for Windows; IBM Corporation: Armonk, NY, USA, 2017.

26. Hojaji, E.; Zavoshy, R.; Noroozi, M.; Jahanihashemi, H. Assessment of household food security and its relationship with some pregnancy complications. J. Maz. Univ. Med. Sci. 2015, 25, 87-98.

27. Aydin, H.; Çelik, Ö.; Yazici, D.; Altunok, Ç.; Tarçin, Ö.; Deyneli, O.; Sancak, S.; Kiyici, S.; Aydin, K.; Yildiz, B.O. Prevalence and predictors of gestational diabetes mellitus: A nationwide multicentre prospective study. Diabet. Med. 2019, 36, $221-227$. [CrossRef]

28. Parveen, M.; Ismaile, M.; Masood, R. Obesity as a predictor of adverse maternal outcomes among pregnant women of a rural community. Pakistan J. Med. Health Sci. 2017, 11, 938-941.

29. Vidanalage, C.K.; Senarth, U.; Silva, K.; Lekamge, U.; Liyanage, I. Effects of initial body mass index on development of gestational diabetes in a rural Sri Lankan population: A case-control study. Diabetes Metab. Syndr. Clin. Res. Rev. 2016, 10, S110-S113. [CrossRef] 
30. Iyoke, C.A.; Ugwu, G.O.; Ezugwu, F.O.; Lawani, O.L.; Onyebuchi, A.K. Retrospective cohort study of the effects of obesity in early pregnancy on maternal weight gain and obstetric outcomes in an obstetric population in Africa. Int. J. Womens Health 2013, 5, 501-507. [CrossRef]

31. Kanguru, L.; Bezawada, N.; Hussein, J.; Bell, J. The burden of diabetes mellitus during pregnancy in low- and middle-income countries: A systematic review. Glob. Health Act. 2014, 7, 23987. [CrossRef] [PubMed]

32. Dolin, C.D.; Gross, R.S.; Deierlein, A.L.; Berube, L.T.; Katzow, M.; Yaghoubian, Y.; Brubaker, S.G.; Messito, M.J. Predictors of gestational weight gain in a low-income hispanic population: Sociodemographic characteristics, health behaviors, and psychosocial stressors. Int. J. Environ. Res. Public Health 2020, 17, 352. [CrossRef] [PubMed]

33. Yaemsiri, S.; Olson, E.C.; He, K.; Kerker, B.D. Food concern and its associations with obesity and diabetes among lower-income New Yorkers. Public Health Nutr. 2011, 15, 39-47. [CrossRef] [PubMed]

34. Wilde, P.E.; Llobrera, J.; Valpiani, N. Household food expenditures and obesity risk. Curr. Obes. Rep. 2012, 1, 123-133. [CrossRef]

35. Sharpe, P.A.; Whitaker, K.; Alia, K.A.; Wilcox, S.; Hutto, B. Dietary intake, behaviors and psychosocial factors among women from food-secure and food-insecure households in the United States. Ethn. Dis. 2016, 26, 139-146. [CrossRef]

36. López-Cepero, A.; Frisard, C.; Bey, G.; Lemon, S.C.; Rosal, M.C. Association between food insecurity and emotional eating in Latinos and the mediating role of perceived stress. Public Health Nutr. 2019, 23, 642-648. [CrossRef] [PubMed]

37. Galesloot, S.; McIntyre, L.; Fenton, T.; Tyminski, S. Food insecurity in canadian adults: Receiving diabetes care. Can. J. Diet. Pr. Res. 2012, 73, e261-e266. [CrossRef] [PubMed]

38. Leung, C.W.; Epel, E.S.; Ritchie, L.D.; Crawford, P.B.; Laraia, B.A. Food insecurity is inversely associated with diet quality of lower-income adults. J. Acad. Nutr. Diet. 2014, 114, 1943-1953.e2. [CrossRef] [PubMed]

39. Correll, M. Getting fat on government cheese: The connection between social welfare participation, gender, and obesity in America. Duke J. Gend. Law Policy 2010, 18, 45-77.

40. Hamrick, K.S.; Andrews, M. SNAP Participants' eating patterns over the benefit month: A time use perspective. PLoS ONE 2016, 11, e0158422. [CrossRef] [PubMed]

41. Whiteman, E.D.; Chrisinger, B.W.; Hillier, A. Diet quality over the monthly supplemental nutrition assistance program cycle. Am. J. Prev. Med. 2018, 55, 205-212. [CrossRef]

42. Dhurandhar, E.J. The food-insecurity obesity paradox: A resource scarcity hypothesis. Physiol. Behav. 2016, 162, 88-92. [CrossRef]

43. Nettle, D.; Andrews, C.; Bateson, M. Food insecurity as a driver of obesity in humans: The insurance hypothesis. Behav. Brain Sci. 2016, 40, e105. [CrossRef] [PubMed]

44. Laraia, B.; Epel, E.; Siega-Riz, A.M. Food insecurity with past experience of restrained eating is a recipe for increased gestational weight gain. Appetite 2013, 65, 178-184. [CrossRef] [PubMed]

45. Jones, A.D.; Mundo-Rosas, V.; Cantoral, A.; Levy, T.S. Household food insecurity in Mexico is associated with the co-occurrence of overweight and anemia among women of reproductive age, but not female adolescents. Matern. Child Nutr. 2016, 13, e12396. [CrossRef]

46. Gubert, M.B.; Spaniol, A.M.; Bortolini, G.A.; Pérez-Escamilla, R. Household food insecurity, nutritional status and morbidity in Brazilian children. Public Health Nutr. 2016, 19, 2240-2245. [CrossRef]

47. Gross, R.S.; Mendelsohn, A.L.; Fierman, A.H.; Racine, A.D.; Messito, M.J. Food insecurity and obesogenic maternal infant feeding styles and practices in low-income families. Pediatrics 2012, 130, 254-261. [CrossRef] [PubMed]

48. Noor, M.I. The nutrition and health transition in Malaysia. Public Health Nutr. 2002, 5, 191-195. [CrossRef] [PubMed]

49. Lim, H.M.; Chee, H.; Kandiah, M.; Shamsuddin, K.; Jamaluddin, J.; Nordin, N.; Shuib, R. Dietary and other factors associated with overweight among women workers in two electronics factories in selangor. Malays. J. Nutr. 2003, 9, 105-124. [PubMed]

50. Sharifi, N.; Dolatian, M.; Mahmoodi, Z.; Abadi, F.M.N.; Mehrabi, Y. The relationship between social support and food insecurity in pregnant women: A cross-sectional study. J. Clin. Diagn. Res. 2017. [CrossRef]

51. Yadegari, L.; Dolatian, M.; Mahmoodi, Z.; Shahsavari, S.; Sharifi, N. The relationship between socioeconomic factors and food security in pregnantwomen. Shiraz E Med. J. 2017, 18, e41483. [CrossRef]

52. Dibaba, Y.; Fantahun, M.; Hindin, M.J. The association of unwanted pregnancy and social support with depressive symptoms in pregnancy: Evidence from rural Southwestern Ethiopia. BMC Pregnancy Childbirth 2013, 13, 135. [CrossRef]

53. McLeod Rivera, W.; Qamar, M.K. Agricultural Extension, Rural Development and the Food Security Challenge; Food and Agriculture Organization of the United Nations: Rome, Italy, 2003.

54. Radimer, K.L.; Olson, C.M.; Campbell, C.C. Development of Indicators to Assess Hunger. J. Nutr. 1990, 120, 1544-1548. [CrossRef]

55. Radimer, K.L.; Olson, C.M.; Greene, J.C.; Campbell, C.C.; Habicht, J.-P. Understanding hunger and developing indicators to assess it in women and children. J. Nutr. Educ. 1992, 24, 36S-44S. [CrossRef] 